\title{
Delayed-response performance by the squirrel monkey'
}

\section{F. Robert Treiehler KENT STATE UNIVERSITY}

\begin{abstract}
Abstraet
Five squirrel monkeys were tested on delayed-response performance at delays of from 1 to $50 \mathrm{sec}$. Gradually increasing the delay durations did not yield performances that were much different from those where several delays were randomly presented within a session. Near-asymptotic performance was obtained after approximately 400-600 trials and the function describing performance at different delay intervals was strikingly like that of the rhesus macaque.
\end{abstract}

\section{Problem}

The delayed-response performance of a variety of species has been reported and the present investigation attempted to assess performance on this task by the squirrel monkey. The undertaking appears appropriate in view of the relationship between this task and neurological deficits, since this animal possesses a brain particularly suited to surgical manipulation because of its lissencephalic (unconvoluted) structure.

Previous evaluations of squirrel monkey delayedresponse performance (Miles \& Blomquist, 1960; French, 1959) have been undertaken either in conjunction with surgical procedures or where choice determinants were assayed, and in neither case were preoperative performance variables of primary concern. The present experiment attempted to assess the effects of delay duration, amount of training, and training techniques on the performances of intact animals. Some comparisons of squirrel monkey results with those of investigations where other species were used in evaluating similar performance variables were undertaken.

\section{Method}

Four male and two female mature squirrel monkeys (Saimiri scuireus) served as subjects in this experiment. One male $S$ failed to show other than chance performance after 700 training trials and was discarded.

All Ss were initially trained to displace objects to obtain grape sections in a modified WGTA and this required from two to nine daily sessions involving 20 trials per session. A maximum of three zero-delay sessions were next imposed and, finally, all Ss performed 100 pre-training trials (5 days) with 1 -sec. delays. Three Ss were then assigned to a condition wherein five-delay intervals $(1,3,6,9$, and 12 sec.) were each presented randomly within a session with the restriction that each interval occur twice at each position. This procedure was continued for 500 trials. The other two animals performed 100 trials (5 days) at the shortest delay, then progressed to the next longer delay for 100 more trials, etc., through the five delay intervals. The two conditions have previously been used with rhesus monkeys (Meyer et al., 1951) and have been termed "random"' and "ascending," respectively. Both groups were subsequently tested by the same procedures on delays of $18,24,30,40$, and $50 \mathrm{sec}$.

At the end of this period one animal died and the remaining Ss were all retested by the ascending method for 100 trials at each interval of $1,3,9,18,30$, and 50 sec.

The procedure on individual trials involved conspicuous presentation of a grape section in the center of the retracted tray, subsequent placement in one of the foodwells, and covering of both wells with identical test objects (black rubber stoppers). An opaque screen was then lowered and the tray moved forward. At the end of this delay interval the screen was raised and the $\mathrm{S}$ was allowed $15 \mathrm{sec}$. in which to displace one object.

Positional placement of the reinforcer varied according to one of five different Gellerman series on the five days of each 100-trial block.

\section{Results}

The solid and broken lines of Fig. 1 display the mean per cent correct responses obtained by the ascending and random groups at each of the 10 delay intervals. The plotted triangles indicate performances during the retest series by the four Ss on ascending method. Each point is determined by the mean of 100 trials by each of the Ss in the designated sample sizes.

Randomization tests for independent samples yield no significant differences between the ascending and random conditions of the initiàl series at any delay intervals, although inspection of the data reveals divergent

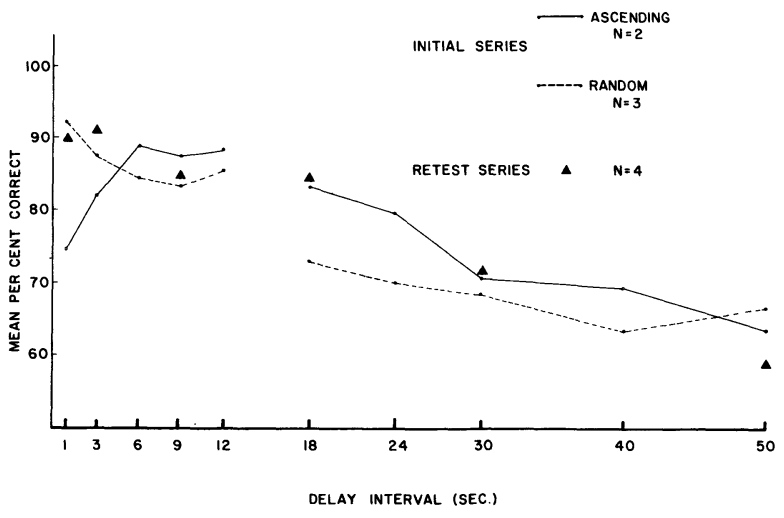

Fig. 1. Delayed-response performance (\% correct) at the various delay intervals. 
results, particularly at the 1- and 18-sec. delays. Significant differences in performance as a function of delay duration are observed in the retest series (KruskalWallis $\mathrm{H}=14.76, \mathrm{p}<.02)$.

\section{Discussion}

The lack of significant differences between ascending and random training conditions concurs with results observed by Meyer et al., (1951) using rhesus monkeys. The present results, however, appear to be influenced by several other variables.

First, a comparison of initial series performances shows an increase in correct responses by the ascending group through the first three intervals, while the random group exhibits a decrease. This difference is attributable to failure to have reached asymptotic levels of performance, since scores for the random group show a similar increasing function if plotted with number of trials as an abscissa. Scores obtained by the ascending method in the retest series (after 1,000 trials) fail to show this effect and it is concluded that a period of approximately 400 to 600 trials is necessary for nearasymptotic performance. When compared to similar results obtained with the marmoset and the macaque (Miles, 1957), the data on numbers of trials required for this level of performance are more like those of macaques than marmosets.

The apparent, but non-significant, differences between initial series performances by the two training procedure groups at 18 and $24 \mathrm{sec}$. are attributable to contrasting intrasession task difficulty. With random presentation, delays of as much as $50 \mathrm{sec}$. are presented within the same daily sessions as the relatively brief delays and about the same level of performance is obtained on all intervals using this procedure. When a series of progressively longer durations is imposed every 100 trials, no such general decrement is observed. The significant effect of delay duration in the retest series is similar to the rhesus monkey results of Meyer et al., (1951) where comparably long delay intervals were imposed.
Meyers et al., (1962) have compiled comparable measures of the performance of cats, marmosets, and rhesus monkeys on delayed-response and have also compared the performance of these three species and the squirrel monkey on learning-set problems. When the present data are noted in this context we find that squirrel monkey delayed-response performance is substantially superior to that of the marmoset and comes close to that of the rhesus macaque. In learning-set performance, however, quite the opposite result is observed. Rhesus performance stands well above that of both the other primates and these two appear to be only slightly superior to the cat. It is thus concluded that although the rank order of performances is the same on the different learning tasks, they differentially discriminate comparative abilities.

\section{References}

FRENCH, G. M. Performance of squirrel monkeys on variants of delayed response. J. comp. physiol. Psychol., 1959, 52, 741-745.

MEYER, D. R., HARLOW, H. F., \& SETTLAGE, P. H. A survey of delayed-response performance by normal and brain-damaged monkeys. J. comp. physiol. Psychol., 1951, 44, 17-25.

MEYERS, W. J., McQUISTON, M. O., \& MILES, R. C. Delayed-response and learning-set performance of cats. J. comp. physiol. Psychol., 1962, 55, 515-517.

MILES, R. C. Delayed response learning in the marmoset and the macaque. J.comp.physiol. Psychol., 1957, 50, 352-355.

MILES, R. C., \& BLOMQUIST, A. J. Frontal lesions and behavioral deficits in monkey. J. Neurophysiol., 1960, 23, 471-484.

\section{Note}

1. The present experiment was partially supported by funds obtained under grant No. MF-13,048 from the National Institute of Mental Health. 